\title{
Pelatihan Penggunaan Microsoft Office Bagi Siswa SMPS St. Yosef Maubesi
}

\author{
Yosep P.K Kelen, Yasinta O.L Rema, Renaldi Y. Kolloh, Valerianus Naat, Elsa M.Benolon, \\ Stefania Y.Nule \\ Prodi Teknologi Informasi, Universitas Timor, Jl. El Tari Km.9, Kefamenanu, 85613 \\ E-mail: rema.ivana@gmail.com
}

\begin{abstract}
Abstrak - Penggunakan media pembelajaran oleh peserta didik salah satunya Microsoft Office menjadi sebuah kemampuan dan keterampilan yang wajib dimiliki dalam era globalisasi dan juga dalam pelaksanaan pembelajaran online. Melalui pelajaran TIK di sekolah, menjadi salah satu wadah siswa-siswi untuk belajar menggunakan Microsoft Office. Namun sempat dihapusnya mata pelajaran TIK menjadi salah satu faktor berkurangnya keterampilan siswa-siswi SMPS St. Yosef dalam menggunakan perangkat lunak Microsoft Office untuk pembelajaran sehari-hari. Melalui kegiatan pengabdian kepada masyarakat (PkM) kami meberikan pelatihan kepada siswa-siswi SMPS St. Yosef Maubesi sebagai solusi terhadap rendahnya kemampuan mereka dalam menggunakan Microsoft Office terutama Microsoft office Word, Excel dan Powerpoint. Pelatihan dilakukan dalam tiga tahap meliputi; tahap pertama berupa wawancara, diskusi dan pembagian kuisioner awal untuk mengetahui sejauh mana pengetahuan dan keterampilan mahasiswa dalam menggunakan Microsof Office. Tahap kedua merupakan tahap pelatihan dalam bentuk pratikum Microsoft Office khususnya Ms. Word, Ms. Excel, dan Ms. Powerpoint sesuai dengan modul telah diberikan. Tahap akhir berupa evalusi dengan cara penyebaran kuisioner terhadap peserta pelatihan. Melalui kegiatan pelatihan ini selain dapat memaksimalkan penggunaan laboratorium sekolah untuk bimbingan dan pelatihan Microsoft Office, juga meningkatkan intensitas pelatihan karena telah tersedia modul atau materi ajar yang telah dibagikan kepada semua peserta pelatihan. Melalui kegiatan PkM ini juga, dapat meningkatkan pengetahuan dan keterampilan peserta didik khususnya siswa-siswi SMPS St. Yosef Maubesi dalam menggunakan Microsoft Office (Word, Excel dan Powerpoint) dalam kegiatan pembelajaran sehari-hari.
\end{abstract}

Kata kunci-Microsoft Office, PkM, SMPS St. Yosef Maubesi

\begin{abstract}
The use of learning media by students, one of which is Microsoft Office, is an ability and skill that must be possessed in the era of globalization and also in the implementation of online learning. Through ICT lessons in schools, it becomes a place for students to learn to use Microsoft Office. However, the elimination of ICT subjects was one of the factors in reducing the skills of students at SMPS St. Yosef in using Microsoft Office software for daily learning. Through community service activities (PkM), we provide training to students of SMPS St. Yosef Maubesi as a solution to their low ability to use Microsoft Office, especially Microsoft office Word, Excel and Powerpoint. The training is carried out in three stages including; The first stage was interviews, discussion and distribution of initial questionnaires to determine the extent of students' knowledge and skills in using the Microsof Office. The second stage is a training stage in the form of a Microsoft Office practice, especially Ms. Word, Ms. Excel, and Ms. Powerpoint according to the module has been given. The final stage is evaluation by distributing questionnaires to training participants. Through this training activity, in addition to maximizing the use of school laboratories for Microsoft Office guidance and training, it also increases the intensity of training because modules or teaching materials are available that have been distributed to all training participants. Through this PkM activity, it can also improve the knowledge and skills of students, especially students of SMPS St. Yosef Maubesi in using Microsoft Office (Word, Excel and Powerpoint) in daily learning activities.
\end{abstract}

Keywords - Microsoft Office, PkM, SMPS St. Yosef Maubesi

\section{PENDAHULUAN}

Informasi dan Komunikasi pada revolusi Industri 4.0 berkembang dengan cepat di semua bidang kehidupan tak terkecuali dunia pendidikan. Oleh karena itu penggunaan perangkat teknologi Informasi dan Komputer seperti Microsoft Office dalam kegiatan belajar dan mengajar menjadi sebuah keharusan agar peserta didik mampu menyerap informasi dengan maksimal dan juga meningkatkan pengalaman belajar dan kreativitas mereka [1] [2].

Penggunaan Microsoft Office (Word, Excel dan Powerpoint) semakin meningkat dengan adanya wabah Covid 19 yang mengharuskan proses pembelajaran lebih banyak dilakukan secara online, yang salah satunya mengharuskan siswa/i mengerjakan tugas-tugas mereka menggunakan Microsoft Office (Word, Excel dan Powerpoint). 
Pelajaran TIK (Teknologi Informasi dan Komunikasi) menjadi salah satu pelajaran dalam kurikulum KTSP yang membekali peserta didik untuk bisa mengoperasikan komputer dan juga menggunakan Microsoft office. Mata pelajaran TIK juga mempelajari tentang sejarah perkembangan teknologi dan komunikasi dari yang sangat sederhana hingga berkembang menjadi seperti saat ini [3]. Microsoft Office juga menjadi salah satu materi yang diberikan dalam pelajaran TIK. Namun dalam perkembangannya kurikulum KTSP tidak digunakan lagi dan digantikan dengan kurikulum 2013. Dengan penerapan kurikulum tersebut menyebabkan pelajaran TIK dihapus dan hanya dijadikan sebagai bimbingan. Hal ini sangat berdampak terhadap kemampuan peserta didik dalam penggunaan perangkat komputer. Terutama siswa/i dari daerah terpencil dan keluarga tidak mampu yang hanya mengandalkan sekolah sebagai tempat mereka untuk belajar menggunakan komputer dan Microsoft Office (Word, Excel dan Powerpoint) [4].

SMPS St. Yosef Maubesi sebagai salah satu sekolah menengah swasta pertama di Kabupaten TTU telah memiliki laboratorium komputer. Namun penggunaannya semakin berkurang dan tidak rutin sejak dihapusnya pelajarin TIK. Laboratorium komputer tersebut hanya digunakan untuk menghadapi persiapan ujian akhir berbasis (UNBK). Hal ini menjadi salah satu faktor kurangnya kemampuan peserta didik dalam penguasaan dan juga keterampilan penggunaan Microsoft Office [5].

Dampaknya sangat terasa terhadap kemampuan siswa dalam mengerjakan tugas-tugas dalam pembelajaran online yang diberikan oleh Guru yang mengharuskan mereka mengerjakan tugas-tugas tersebut menggunakan Microsoft Office (Word, Excel dan Powerpoint). Berdasarkan permasalahan tersebut di atas, maka dilakukan pelatihan penggunaan Microsof Office guna peningkatan kemampuan peserta didik dalam pengusaan Microsoft Office khususnya Microsoft Office Word, Excel dan Powerpoint) [6] [7].

\section{METODE}

Mitra PKM ini adalah siswa/siswi SMPS St, Yosef Maubesi yang merupakan salah satu sekolah menengah pertama swasta yang terletak di Kecamatan Maubesi Kabupaten Kefamenanu Provinsi Nusa Tenggara Timur. Sekolah ini memiliki sebuah laboratorium komputer dengan 30 unit komputer di dalamnnya. Bentuk pelatihan berupa pratikum diberikan kepada 30 peserta pelatihan disesuaikan dengan jumlah unit komputer yang ada di labroratorium komputer dan juga menyesuaikan dengan kondisi wabah Covid 19.
Dalam semua kegiatan tersebut tim pengabdi tetap berusaha melaksanakannya dengan tetap mengikuti protokol kesehatan selama menghadapi wabah Covid 19. Antara lain pembagian masker gratis kepada peserta latihan, penggunaan hand sanitizer sebelum dan sesudah kegiatan, sterilisasi rungan laboratorium komputer sebelum digunakan, dan tetap menjaga jarak.

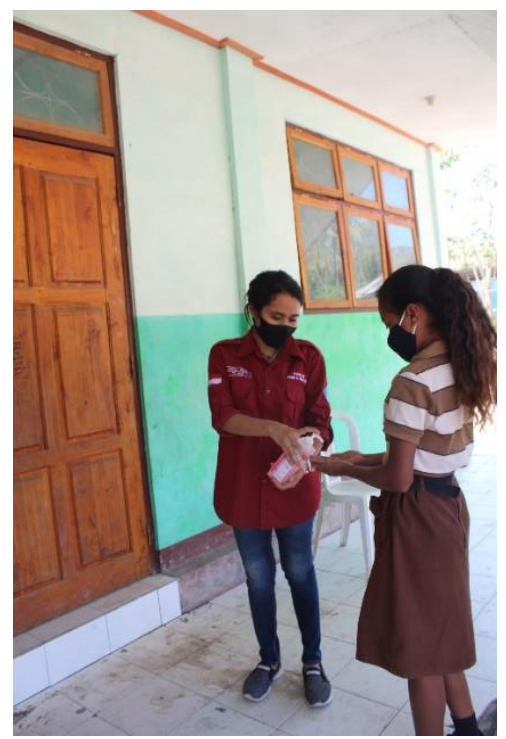

Gambar 1. Penerapan Protokol kesehatan dalam kegiatan PKM

Kegiatan Pengabdian Kepada Masyaraka ini, berlangsung dalam tiga tahap. Tahap pertama tim pengabdi memberikan pretest dalam bentuk kuisioner awal untuk mengetahui sejauh mana penguasaan siswa-siswi terhadap Microsoft Office (Word, Excel dan Powerpoint). Selanjutnya pada tahap kedua diberikan bimbingan atau pelatihan penggunaan Microsoft Office (Word, Excel dan Powerpoint), sedangkan tahap akhir dilakukan evaluasi hasil pelatihan (posttest) berupa kuisioner terhadap siswa-siswi SMPS St. Yosef Maubesi yang mengikuti pelatihan Microsoft Office (Word, Excel dan Powerpoint).

\section{HASIL DAN PEMBAHASAN}

Pada tahap pertama, tim Pengabdi melakukan beberapa investigasi melalui wawancara, diskusi dan penyebaran kuisioner terhadap siswa/i untuk mengetahui sejauh mana kemampuan mereka dalam menggunakan Microsoft Office (Word, Excel dan Powerpoint). 


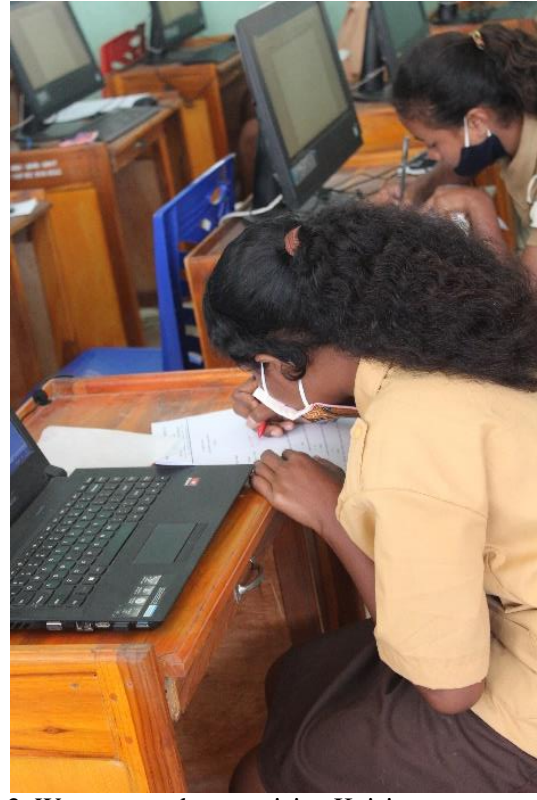

Gambar 2. Wawancara dan pengisian Kuisioner

Berikut beberapa masalah yang dihadapi :

a. Minimnya kemampuan peserta didik dalam penguasaan Microsoft Office (Word, Excel dan Powerpoint).

b. Ketidakmampuan peserta didik untuk mengerjakan tugas-tugas sekolahnya dengan menggunakan Microsoft Office (Word, Excel dan Powerpoint).

c. Belum adanya modul atau materi ajar tentang penggunaan Microsoft Office (Word, Excel dan Powerpoint), yang dapat membantu siswa untuk belajar menggunakan Microsoft Office (Word, Excel dan Powerpoint).

d. Minimanya kegiatan pendampingan /bimbingan pelatiahan Microsoft Office (Word, Excel dan Powerpoint) yang diterima oleh siswa/i SMPS St. Yosef Maubesi

Dari rincian permasalahan di atas dapat disimpulkan permasalah utama yang dihadapi siswa/i bahan permasalahn utama yang dihadapi oleh siswa/i SMPS St. Yosef Maubesi adalah kuranngnya pelatihan dan belum adanya modul atau materi ajar tentang Microsoft Office (Word, Excel dan Powerpoint).

Pada tahap kedua diberikan pelatihan teknis tentang penggunaan Microsoft Office (Word, Excel dan Powerpoint). Modul atau materi ajar dibagikan kepada peserta pelatihan. Selanjutnya tim pengabdi memberikan pelatihan penggunaan Microsoft Office (Word, Excel dan Power Point). Pelatihan tesrsebut berupa pembuatan dokumen sederhana dengan $M s$. Word, perhitungan aritmatikan dengan menggunakan sederhana dengan menggunakan $M s$. Excel, dan juga pembuatan presentasi dengan menggunakan Ms. Powerpoint. Peserta mengikuti semua pelatihan tersebut dengan antusias dengan mendengarkan pengarahan dari tim pengabdi dan mengikuti tahapan - tahapan sesuai modul atau materi ajar yang telah diberikan [8] [9].

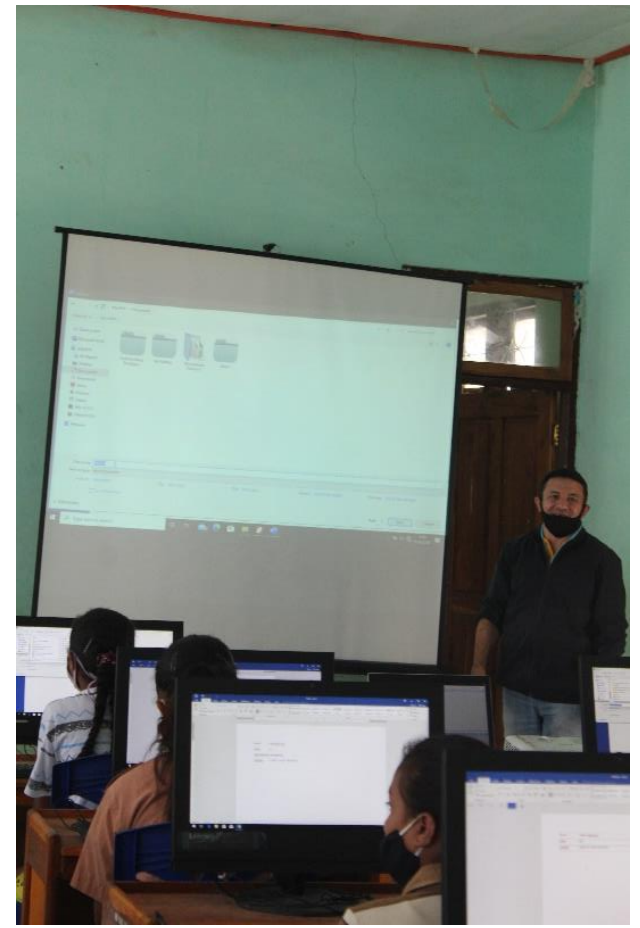

Gambar 3. Kegiatan pelatihan

Setelah melakukan kegiatan pelatihan, tahap selanjutnya merupakan tahap evaluasi. Pada tahap ini peserta pelatihan diberikan kuisioner sebagai bentuk evalusi untuk mengetahui pengetahuan mereka dan dan keyakinam mereka untuk menggunakan Microsoft Office (Word, Excel dan Powerpoint) dalam mengerjakan tugas-tugas yang diberikan [10].

Berikut solusi dan luaran dari kegiatan PkM yang telah terwujud :

a. Pelatihan yang diberikan memberikan kepercayaan diri kepada siswa-siswi SMPS St. Yosef Maubesi untuk mengerjakan tugas tugas sekolah yang diberikan oleg Guru dengan menggunakan Microsoft Office (Word, Excel dan Powerpoint). Melalui pelatihan siswa-siswi mampu membuat dokumen sederhana dengan menggunakan Ms. Office Word, membuat perhitungan aritmatika dengan Ms. Excel dan juga mampu membuat presentasi tugas menjadi lebih menarik dengan menggunkan Ms. Powerpoint. Diharapkan pelatihan lebih berkesinambungan dengan memanfaatkan fasilitas laboratorium komputer yang ada.

b. Dengan pemberian modul atau materi ajar kepada siswa-siswi membantu mereka untuk terus berlatih dengan menggunakan laboratorium yang tersedia sehingga dengan 
sendirinya melalui pelatihan dan bimbingan yang terus berjalan kemampuan siswa untuk mengoperasikan atau menggunakan Microsoft Office dpat ditingkatkan.

Kegiatan pelatihan penggunaan Microsoft Office (Word, Excel dan Powerpoint) telah memberikan dampak/perubahan kepada pserta kegiatan. Berikut tabel kondisi siswa-siswi peserta pelatihan sebelum dan sesudah mengikuti kegiatan PkM

Tabel 1. Kondisi Siswa/i SMPS St. Yosef Maubesi sebelum dan setelah kegiatan PKM

\begin{tabular}{|c|c|}
\hline Sebelum PkM & Setelah PkM \\
\hline $\begin{array}{l}\text { Siswa-siswi belum memiliki } \\
\text { modul/materi ajar tentang } \\
\text { penggunaan Microsoft Office } \\
\text { khususnya Microsoft Office } \\
\text { Word, Excel, dan juga } \\
\text { Powerpoint. }\end{array}$ & $\begin{array}{l}\text { Siswi/-siswi telah memiliki } \\
\text { modul atau materi ajar tentang } \\
\text { penggunaan Microsoft office } \\
\text { (Word, Excel, dan Powerpoint). }\end{array}$ \\
\hline 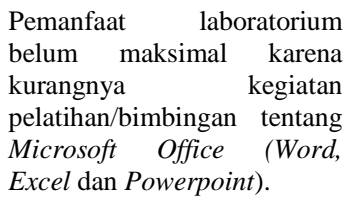 & $\begin{array}{l}\text { Dengan ketersediaan modul } \\
\text { atau materi ajar, kegiatan } \\
\text { pelatihan menjadi lebih intens } \\
\text { dengan memanfaatlkan fasilitas } \\
\text { laboratorium komputer } \\
\text { sekolah. }\end{array}$ \\
\hline $\begin{array}{l}\text { Siswa-siswi peserta pelatihan } \\
\text { jarang menggunakan } \\
\text { Microsoft Office dalam } \\
\text { mengerjakan tugas-tugas } \\
\text { yang diberikan, karena } \\
\text { kurangnnya penguasaan atas } \\
\text { Microsoft Office itu sendiri. }\end{array}$ & $\begin{array}{l}\text { Siswa-siswi menjadi lebih } \\
\text { yakin dan percaya diri bahwa } \\
\text { dengan mengikuti pelatihan ini } \\
\text { mereka dapat mengerjakan } \\
\text { tugas-tugas sekolah mereka } \\
\text { dengan menggunakan } \\
\text { Microsoft Office }\end{array}$ \\
\hline
\end{tabular}

Meskipun hanya empat orang peserta (13\%) dari dari peserta pelatihan yang memiliki laptop/PC di rumah dan sisanya hanya memiliki smatphone yang dapat mengases Ms. Office secara terbatas, namun mereka yakin bahwa jika diberikan modul atau materi ajar dan juga pelatihan yang rutin, mereka dapat meningkatkan kemampuan mereka dalam menggunakan Ms. Office terutama mengerjakan tugas-tugas yang diberikan.

\section{KESIMPULAN}

Secara keseluruhan dampak yang dirasakan dengan adanya kegiatan PkM ini, dapat meningkatkan pengetahuan dan keterampilan peserta didik khususnya siswa-siswi SMPS St. Yosef Maubesi dalam menggunakan Microsoft Office (Word, Excel dan Powerpoint) dalam kegiatan pembelajaran sehari-hari.

Kegiatan PkM ini tidak hanya berdampak terhadap mitra. Namun juga memberikan pengalaman kepada mahasiswa Teknologi Informasi Universitas Timor yang dilibatkan secara aktif sebagai tim pengabdi. Diharapkan kedepannya mereka mampu terlibat secara aktif untuk menyelesaikan masalah yang ada di masyarakat terutama yang berkaitan dengan penggunaan perangkat lunak Microsoft Office.

\section{UCAPAN TERIMA KASIH}

Kami sebagai penulis mengucapkan limpah terima kasih kepada Lembaga Penelitian dan Pengabdian pada Masyarakat (LPPM) Universitas Timor yang telah memberikan dukungan dana agar program Pengabdian Masyarakat ini dapat berjalan dengan baik dan juga kepada SMPS St. Yosef Maubesi yang bersedia menjadi mitra dalam kegiatan Pengabdian kepada Masyarakat ini.

\section{DAFTAR PUSTAKA}

[1] M. M. Rokhman, S. A. Wibowo, Y. A. Pranoto dan K. A. Widodo, 2018. Pelatihan Pemanfaatan Microsoft Office Pada Staf pengajar di SMPLBN (Sekolah Menengah Pertama Luar Biasa Negeri) Kota Malang, MNEMONIC, vol. 1, no. 1

[2] A. Niati, A. Soelistiyono dan T. Ariefiantoro, 2019. Pengembangan Sumber Daya Manusia melalui Pelatihan Komputer Microsoft Office Excel untuk Meningkatkan Kinerja Perangkat Desa Mranggen, EDIMAS : Education Pengabdian Kepada Masyarakat, vol. 10, no. 01, pp. 105-110

[3] H. I. Pratiwi, 2018. Pelatihan Microsoft Office untuk Karyawan dan Kelompok PKK Kelurahan Sawah Baru Tangerang Selatan, dalam SEMBADHA PKN STAN, Jakarta,

[4] R. Sari, A. Fitriyani dan R. D. Prabandari, 2020. Optimalisasi Penggunaan MS. Word dan MS. Excel Pada Siswa SMP PGRI Astra Insani Bekasi, ABDIMAS, vol. 3, no. 2, pp. 95-104

[5] M. A. Sormin, N. Sahara dan L. Agustina, 2018. Pelatihan Pemanfaatan Perangkat Lunak (Microsoft Office Word, Excel, Power Point) Dalam Kinerja Pengolahan Data di Pemerintahan Desa Bagi Kepala Desa SeKecamatan Batang Angkola, Martabe : Jurnal Pengabdian Masyarakat, vol. 1, no. 2, pp. 78-82, 
[6] M. Wali dan Mukhtar, 2020. Pelatihan Microsoft Excel 2013 Dalam Rangka Membentuk Tenaga Pengajar Yang Profesional, TRIDARMA : Pengabdian Kepada Masyarakat, vol. 3, no. 1

[7] Y. Ikhwani, H. Budiman dan M. Rasyidan, 2015. Pelatihan Aplikasi Microsoft Word 2013 Pada SMP H.A. Johansyah A. Banjarmasin, Journal Al-Ikhlas.

[8] N. P. L. Santiari dan I. G. S. Rahayuda, 2018. Pelatihan Ms. Word Pada SDN 1 Gulingan, Jurnal Pengabdian Masyarakat Borneo, vol. 2, no. 1, pp. 8-13
[9] A. A. Nababan dan M. Jannah, 2019. Pelatihan Microsoft Office Bagi Mahasiswa Di Universitas Medan Area, TRIDARMA : Pengabdian Kepada Masyarakat, vol. 2, no. 2, pp. $67-73$

[10] Z. Azhar, J. Hutahaean, Y. Siagian dan A. Z. Syah, 2019. Pelatihan Microsoft Excel 2010 Pada Siswa Lembaga Kursus Pendidikan (LKP) Mandiri," Jurnal Anadara Pengabdian Kepada Masyarakat, vol. 1, no. 2 
Jati Emas (Jurnal Aplikasi Teknik dan Pengabdian Masyarakat)

Vol. 4 No. 2 Oktober 2020 - e. ISSN: 2550-0821 